\title{
Riau Heritage Digital Library sebagai Sarana Informasi dan Inventaris Warisan Budaya Nusantara berbasis Web
}

\author{
Erlin$^{1}$, Yusuf Nuron ${ }^{2}$, Triyani Arita Fitri ${ }^{3}$, Agustin ${ }^{4}$ \\ 1,2,3,4 Program Studi Teknik Informatika, STMIK Amik Riau \\ Jl. Purwodadi Indah, Km.10, Pekanbaru \\ e-mail: 1erlin@stmik-amik-riau.ac.id, ${ }^{2}$ yusuf_n@stmik-amik-riau.ac.id \\ 3triyani@stmik-amik-riau.ac.id, ${ }^{4}$ agustin@stmik-amik-riau.ac.id
}

\begin{abstract}
Abstrak
Riau memiliki warisan budaya dan warisan alam yang banyak dan beragam yang tersebar disepanjang hamparan wilayah provinsi Riau. Sетиa warisan peninggalan generasi terdahulu yang tak ternilai ini harus dilindungi dengan baik dan diserahkan kepada generasi mendatang untuk diperlakukan sebagai sumberdaya bernilai historis yang sangat tinggi. Namun sampai saat ini belum tersedia suatu wadah yang mampu menampung seluruh data dan informasi mengenai warisan budaya dan warisan alam yang ada di Riau. Hal ini menyebabkan kurangnya minat dan kepedulian generasi muda untuk memelihara, menjaga dan melestarikan kebudayaan setempat. Sulitnya mencari informasi mengenai Riau heritage juga menjadi salah satu faktor yang menghambat sosialisasi pelestarian pusaka Riau kepada semua kalangan. Sebuah situs Riau Heritage Digital Library dirancang untuk mengatasi masalah ini. Situs ini mampu menampilkan seluruh warisan budaya dan warisan alam yang ada di provinsi Riau seperti bangunan kuno dan bersejarah, alam, candi, tarian dan musik tradisional, permainan rakyat dan properti sejarah lainnya. Semua informasi dikemas dalam bentuk digitalisasi dan visual serta dapat di break down berdasarkan wilayah, tipe koleksi dan topik koleksi.
\end{abstract}

Kata kunci: Riau heritage, digital library, informasi, inventaris, website

\begin{abstract}
Riau has a huge and diverse cultural and natural heritage that is spread along the stretch of Riau province. All these priceless legacies of the past generation must be properly protected and handed over to future generations to be treated as very high historical value resources. But until now there has not been a system that is able to store and display all data and information regarding the cultural and natural heritage of Riau province. This has caused a lack of interest and concern of the young generation to preserve and conserve local culture. The difficulty of finding information about the heritage of Riau is also one of the factors that hinder the socialization of Riau's heritage conservation to all circles. A website of Riau Heritage Digital library was designed to overcome this problem. This site is able to display all the cultural and natural heritage such as ancient and historic buildings, nature, temples, dances and traditional music, folk games and other historic properties. All information is packaged in digitalized and visual form and can be broken down by region, collection type and collection topic.
\end{abstract}

Keywords: Riau heritage, digital library, information, inventory, website

\section{Pendahuluan}

Heritage dapat diartikan sebagai warisan (budaya) masa lalu, apa yang saat ini dijalani manusia, dan apa yang diteruskan kepada generasi mendatang [1]. Dalam kalimat lain heritage adalah sesuatu yang seharusnya diestafetkan dari generasi ke generasi, umumnya karena dikonotasikan mempunyai nilai sehingga patut dipertahankan atau dilestarikan keberadaannya. 
Pengertian heritage sebenarnya memiliki makna yang lebih luas. Dalam kamus Oxford [2], heritage ditulis sebagai sejarah, tradisi, dan nilai-nilai yang dimiliki suatu bangsa atau negara selama bertahun-tahun dan dianggap sebagai bagian penting dari karakter suatu bangsa. Sementara Howard [3] memaknai heritage sebagai segala sesuatu yang ingin diselamatkan orang, termasuk budaya material maupun alam.

Riau merupakan bagian wilayah nusantara memiliki warisan budaya dan warisan alam yang sangat banyak dan beragam yang tersebar disepanjang hamparan wilayah provinsi Riau. Semua warisan peninggalan generasi terdahulu yang tak ternilai ini harus dilindungi dengan baik dan diserahkan kepada generasi mendatang untuk diperlakukan sebagai sumberdaya bernilai historis yang sangat tinggi. Sesuai yang diamanatkan dalam Piagam Pelestarian Pusaka Indonesia 2003 [4], perlunya sosialisasi mengenai warisan nusantara kepada semua kalangan agar tumbuh kesadaran bersama untuk memelihara kekayaan pusaka bangsa.

Sejumlah studi telah dilakukan oleh beberapa peneliti terdahulu tentang heritage dan digital library pada beberapa aspek di beberapa negara. Rua and Gilz [5] melakukan penelitian tentang penggunaan metodologi virtual 3D dalam merepresentasikan monumen yang karakteristik dan fungsinya tidak memungkinkan untuk dilakukan studi pemodelan dan survei terpadu. Hasil dari penelitian ini adalah sebuah pembaharuan model otomatis sehingga setiap ada penemuan baru muncul, keseluruhan tahapan model tidak perlu dilakukan ulang. Peneliti lain [6] fokus pada model regresi linier berganda dan model logika fuzzy yang diterapkan untuk memprediksi umur layanan suatu warisan budaya. Hasil yang diperoleh dapat digunakan oleh pemangku kepentingan untuk mengurangi probabilitas kegagalan pemeliharaan. Selanjutnya Dieck and Jung [7] mengaplikasikan augmented reality sebagai inovasi teknologi dalam pelestarian warisan budaya. Hasil penelitian yang diperoleh menunjukkan bahwa augmented reality memiliki nilai ekonomi, sosial, epistemik dari prespektif stake holders internal maupun eksternal. Peneliti lain [8] mempresentasikan pengelompokkan penelitian dibidang digital library dari tahun 1990-2010 untuk memetakan pengetahuan dan ontology perpustakaan digital. Hasil penelitian dalam bentuk review paper ini dapat digunakan untuk berbagai keperluan seperti memperlihatkan bidang utama penelitian pada bidang digital library sekaligus menunjukkan sifat interdisipliner digital library itu sendiri.

Meskipun banyak penelitian yang dilakukan dibeberapa negara yang berbeda tentang heritage dan teknologi yang digunakan, namun berdasarkan pencarian pada database perpustakaan utama dan jurnal online tidak ditemukan suatu studi atau kajian empiris berkaitan dengan sistem informasi dan inventarisasi warisan budaya yang ada di Riau yang telah dipublikasikan sampai saat ini. Fakta ini diperkuat dengan belum tersedianya suatu wadah yang mampu menampung seluruh data dan informasi yang berkaitan dengan Riau heritage. Hal ini menyebabkan kurangnya minat dan kepedulian generasi muda untuk memelihara, menjaga dan melestarian kebudayaan setempat. Sulitnya mencari informasi mengenai Riau heritage juga menjadi salah satu faktor yang menghambat sosialisasi pelestarian pusaka Riau kepada semua kalangan.

Perancangan sebuah situs Riau Heritage Digital Library berbasis web dibangun untuk mengatasi masalah ini. Situs Riau Heritage Digital Library, lebih mempermudah transfer data dan informasi kepada generasi sekarang dan generasi selanjutnya. Selain itu juga bisa digunakan oleh wisatawan yang ingin berkunjung ke Riau dalam hal pencarian informasi mengenai Riau heritage mengingat heritage merupakan salah satu daya pikat wisatawan berkunjung ke suatu wilayah. Semua dokumen di-digitalisasi dan bersama dokumen visual akan menghasilkan inventaris warisan budaya Riau sebagai bagian pusaka Indonesia. Selain itu agar terwujud rekam jejak sejarah, budaya dan peradaban masyarakat Riau sebagai masyarakat yang beradab dan bermartabat. 


\section{Metode Penelitian}

Penelitian ini menggunakan pendekatan Software Development Life Cycle (SDLC) yaitu siklus hidup pengembangan sistem untuk menghasilkan perangkat lunak dengan kualitas tinggi dan biaya rendah dalam kurun waktu yang singkat mencakup rencana terperinci tentang cara mengembangkan, mengubah, memelihara dan mengganti sistem perangkat lunak. Menurut Ruparelia [9], SDLC berupa kerangka kerja konseptual atau proses yang mempertimbangkan struktur tahapan yang terlibat dalam pengembangan sistem dari studi kelayakan awal hingga implementasi dilapangan dan proses pemeliharaannya.

Model SDLC yang digunakan dalam penelitian ini adalah model Waterfall dengan umpan balik iteratif (iterative feedback) yang dikembangkan oleh Royce [10]. Peneliti melakukan minor modifikasi dari model iteratif yang dikembangkan oleh Royce untuk menyesuaikan dengan perkembangan teknologi pengembangan sistem. Gambar 1 berikut merupakan tahapan pengembangan sistem yang dilakukan mulai dari mendefinisikan proyek sampai tahap pemeliharaan yang akan dilakukan proses iteratif secara berkelanjutan.

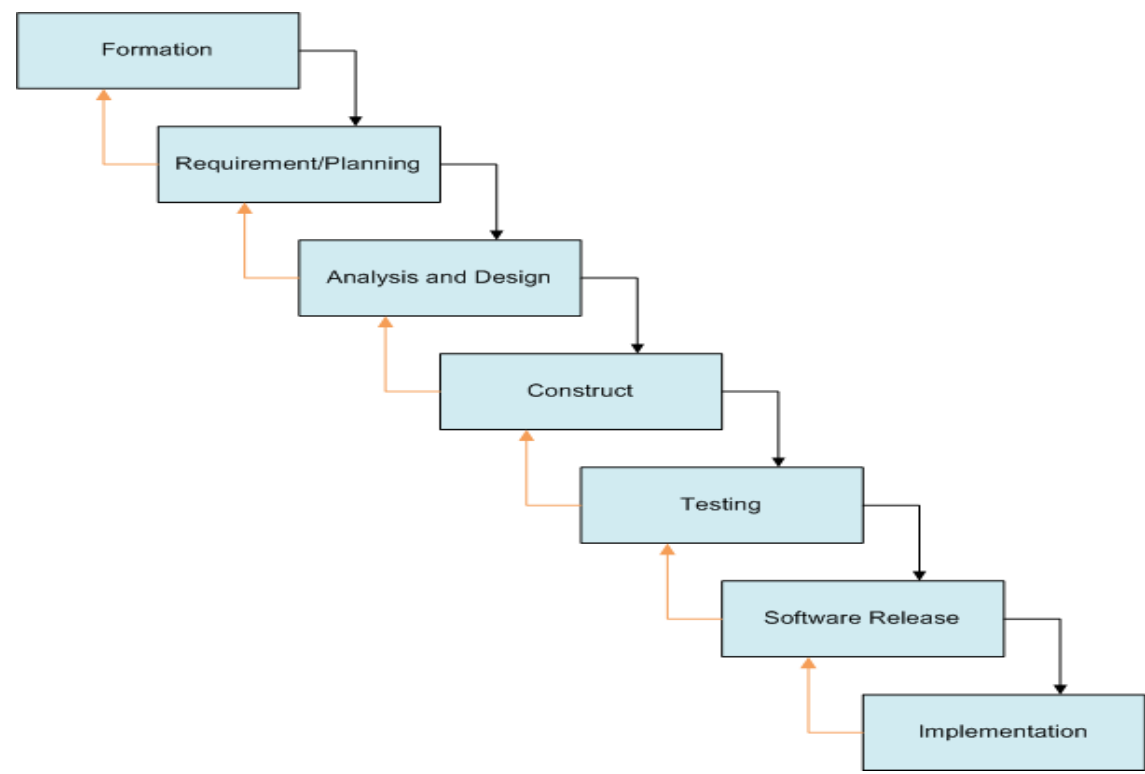

Gambar 1. Model Waterfall dengan Umpan Balik Iteratif [9]

Merujuk kepada model waterfall dengan umpan balik iteratif diatas, penelitian ini menurunkan langkah-langkah pengembangan sistem sebagaimana diperlihatkan pada gambar 2 . Tahap pertama dilakukan inisiasi terhadap sistem yang akan dibangun, dalam hal ini adalah membangun sebuah website Riau Heritage Digital Library. Pada tahapan ini dilakukan estimasi terhadap waktu dan biaya serta sumberdaya lainnya yang berkaitan dengan website yang dikembangkan. Tahap kedua mendefinisikan seluruh kebutuhan perangkat lunak dari sisi user/pengguna dan dari sisi sistem yang dikembangkan. Pada tahapan ini juga dilakukan perkiraan resiko yang dihadapi dan spesifikasi kebutuhan perangkat lunak yang dibuat. Tahap ketiga dilakukan analisa dan perancangan sistem termasuk arsitektur perangkat lunak yang dibangun, selanjutnya melakukan review terhadap rancangan yang telah dibuat dan membuat detail pengembangan website yang dibuat. Tahap keempat adalah tahap membangun website melalui serangkaian coding yang disusun untuk menghasilkan sebuah prototipe dan dilanjutkan dengan review coding yang telah disusun. Tahap kelima adalah tahap ujicoba terhadap website yang dihasilkan. Ujicoba meliputi uji validitas terhadap fungsi dan operasional apakah telah sesuai dengan yang telah dirancang sebelumnya. Apabila telah sesuai dengan spesifikasi dan rancangan, maka masuk ketahap ke enam yaitu tahap rilis website pada kalangan terbatas untuk melihat dan menerima masukan dari semua stakeholder. Tahap terakhir adalah tahap 
implementasi yang dikaitkan dengan proses peningkatan dan pemeliharaan secara berkelanjutan dengan mengikuti tahapan iteratif sesuai dengan model pengembangan yang telah dipilih.

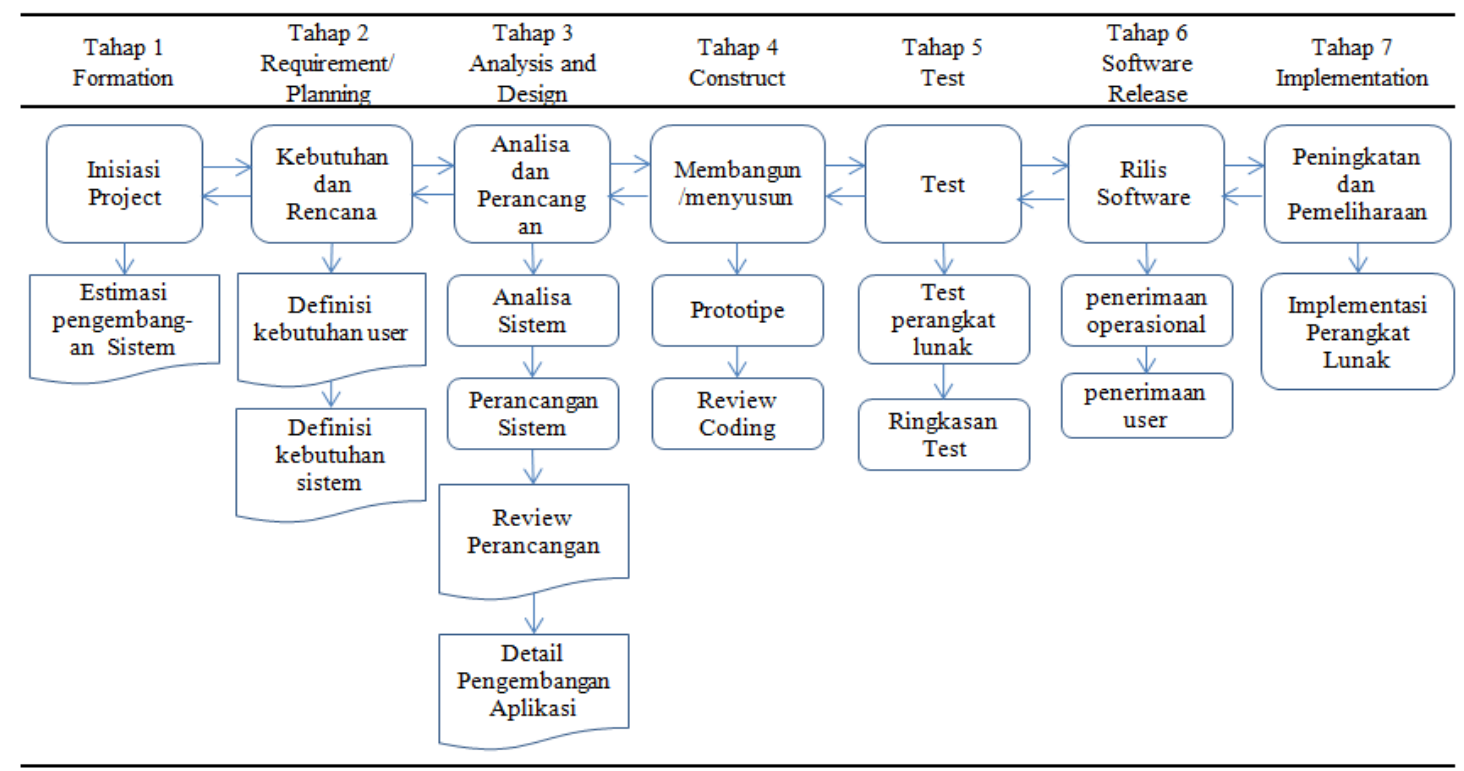

Gambar 2. Tahapan Pengembangan Sistem

\section{Analisa dan Perancangan}

\subsection{Spesifikasi Kebutuhan}

Kebutuhan sistem ditampilkan pada diagram use case seperti diperlihatkan pada gambar 3, yang menunjukkan hubungan antara aktor dan sistem. Berdasarkan diagram use case, terdapat dua aktor yang terlibat dalam sistem, yaitu administrator dan pengguna. Administrator ditugaskan untuk mengelola data master, melakukan penginputan data, input artikel yang berkaitan dengan Riau Heritage serta memvalidasi data tambahan dari pengguna umum/masyarakat. Pengguna dapat melakukan input data warisan budaya dan warisan alam, input data kategori dan kabupaten serta output halaman utama.

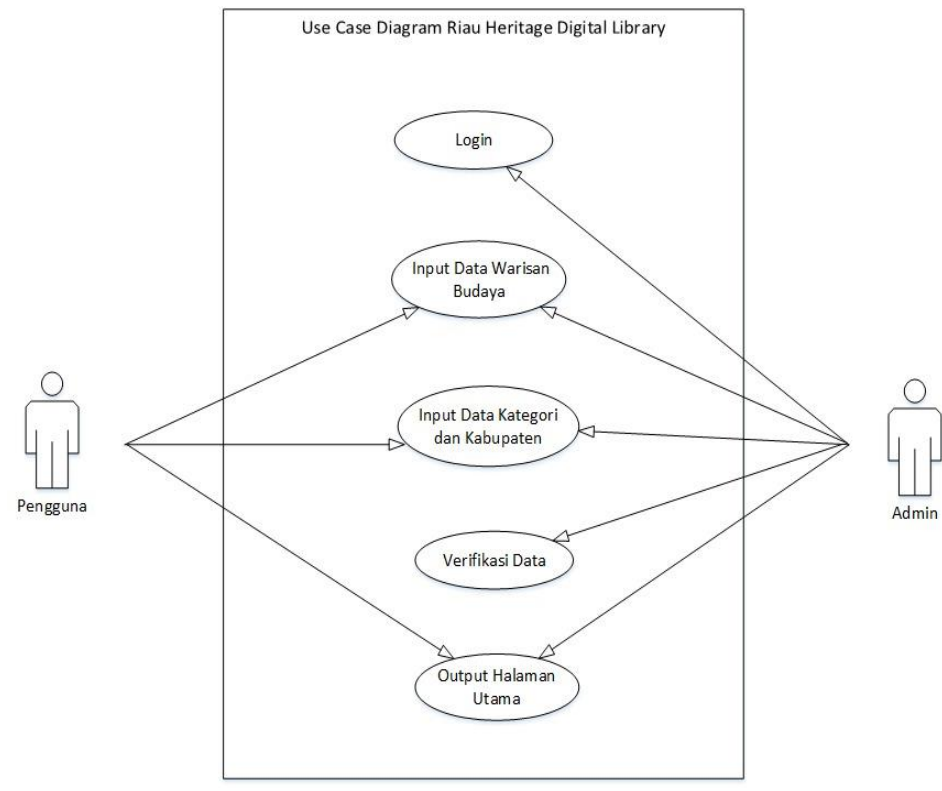

Gambar 3. Use Case Diagram Riau Heritage Digital Library 


\subsection{Rancangan Database}

Database yang digunakan dalam aplikasi ini adalah Structured Query Language (SQL). Logika database tersimpan dalam bentuk file javascript dan sql. Database SQL dapat diakses dengan menggunakan aplikasi yang telah tersimpan di server. Perancangan database ditunjukkan pada gambar 4 yang menampilkan hubungan antara satu tabel dengan tabel lainnya dalam bentuk keterkaitan antara primary key masing-masing tabel. Website ini dibangun menggunakan 5 (lima) tabel yaitu: tabel pustaka, tabel koleksi, tabel kategori, tabel kategori bantu, dan tabel kabupaten.

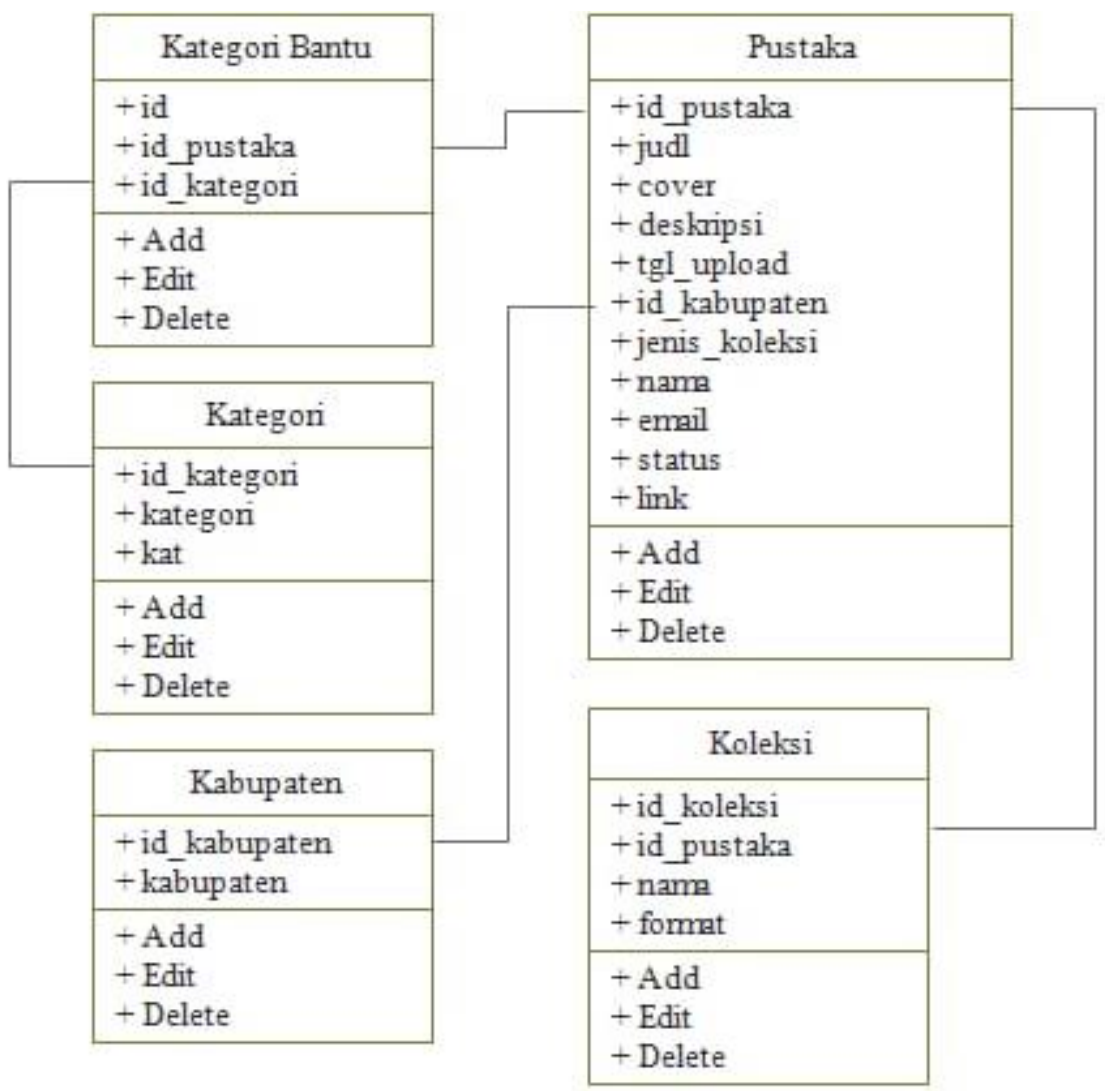

Gambar 4. Rancangan Database Riau Heritage Digital library

\section{Hasil dan Pembahasan}

\subsection{Halaman Menu Utama}

Pada tampilan halaman utama terdapat 5 (lima) menu utama yaitu heritage yang berisi informasi mengenai jenis heritage yang ada di Provinsi Riau, koleksi yang berisi jenis warisan budaya yang ada pada masing-masing kabupaten yang ada di provinsi Riau termasuk pembagiannya berdasarkan kategori, tentang kami yang memuat informasi mengenai sistem yang dibangun beserta tujuannya, kalender event yang memuat informasi mengenai event pariwisata di provinsi Riau dan login admin yang berisi hak akses untuk admin dalam memperbaharui informasi dan database dari sistem yang dibangun. Gambar 5 memperlihatkan tampilan halaman utama.

Terdapat dua aktor yang memiliki hak akses yang berbeda. Administrator dapat melakukan proses penambahan, penghapusan, pengeditan, validasi, pemantauan, dan pengendalian seluruh sistem. Pengguna dapat melihat semua data Riau Heritage yang telah diinput oleh administrator termasuk input data dari masyarakat umum melalui validasi admin. 


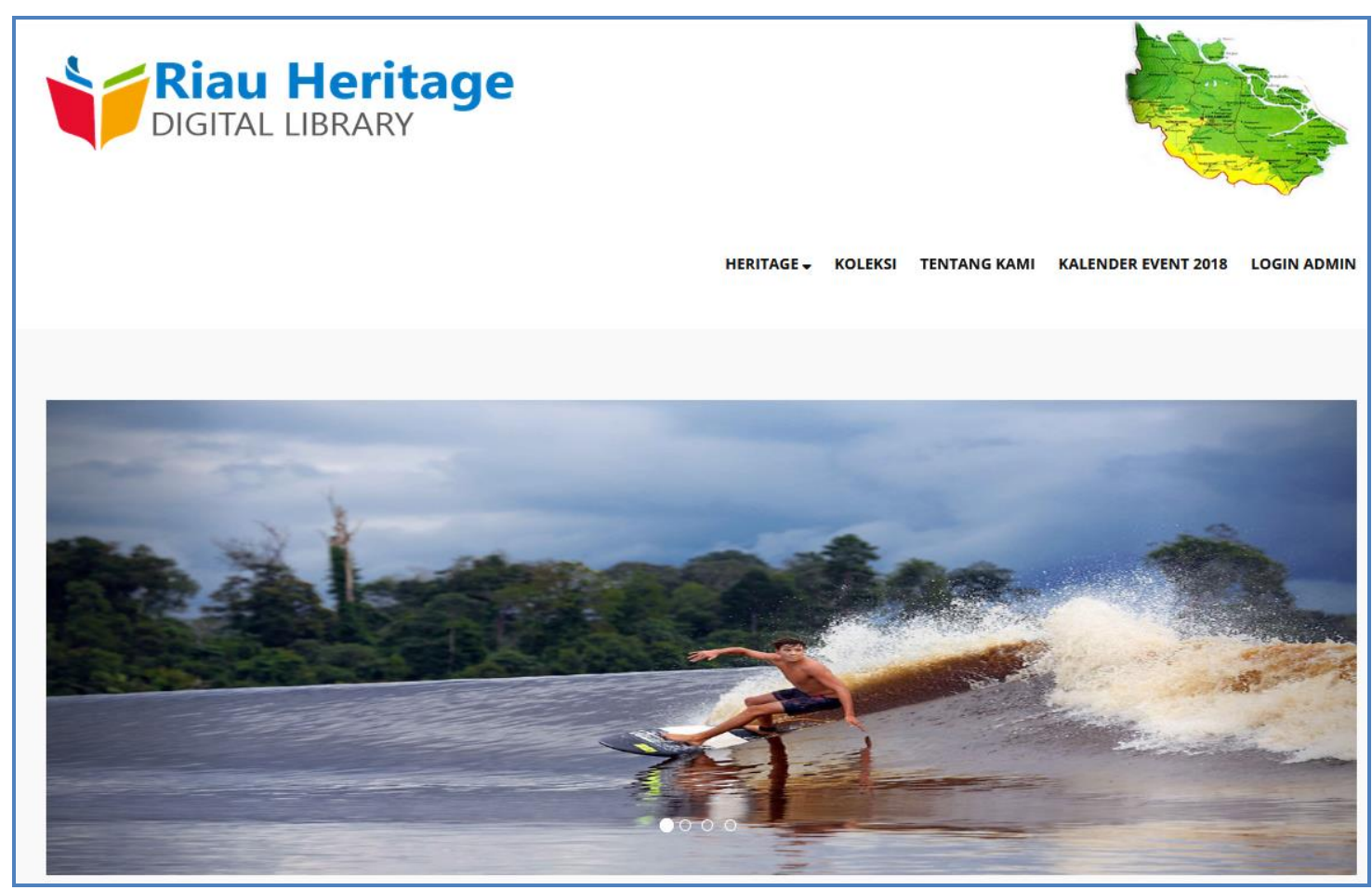

Gambar 5. Tampilan halaman utama

\subsection{Halaman Login Admin}

Admin memiliki otorisasi untuk mengelola seluruh data master yang ada di website. Oleh sebab itu admin memiliki akses ke website dengan menggunakan hak login. Data master yang dikelola oleh admin adalah data warisan budaya dan warisan alam yang berisi daftar macammacam Riau heritage yang telah diinputkan ke sistem, data master kategori dan data master kabupaten yang berisi pengelompokkan data warisan budaya dan warisan alam berdasarkan kategori yang telah ditetapkan dan asal daerah dari warisan tersebut serta menu laporan yang berisi daftar warisan yang terdata di pustaka digital. Menu yang bisa digunakan oleh admin diperlihatkan pada gambar 6, sedangkan pengisian data pada menu utama disajikan pada tabel 1.

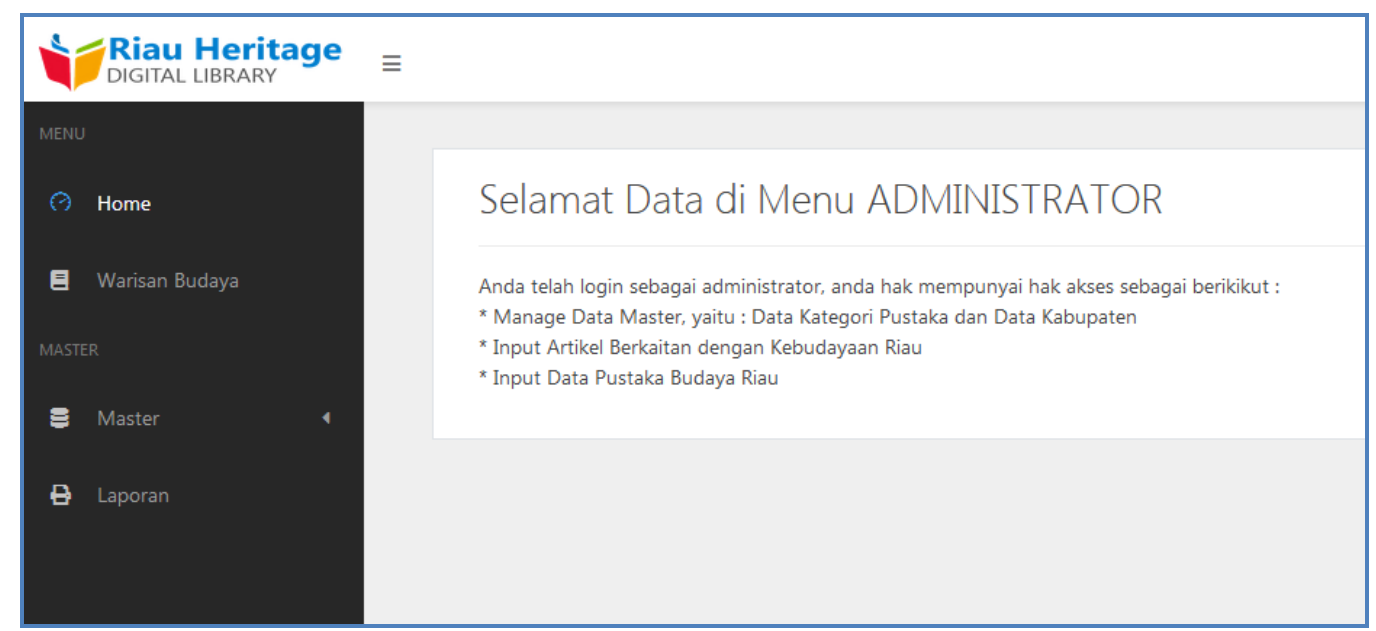

Gambar 6. Tampilan Awal Halaman Admin Riau Heritage Digital library 
Pengisian data pada menu utama dalam situs Riau Heritage Digital Library dikategorikan dalam tiga bagian utama yang terdiri atas warisan budaya, master kategori dan kabupaten serta laporan.

Tabel 1. Penjelasan Menu Situs Riau Heritage Digital Library

\begin{tabular}{|l|l|c|}
\hline \multicolumn{1}{|c|}{ Menu } & \multicolumn{1}{|c|}{ Penjelasan } & Aksi Admin \\
\hline Warisan Budaya & $\begin{array}{l}\text { Daftar macam-macam warisan budaya yang } \\
\text { dimasukkan ke sistem }\end{array}$ & Tambah, edit, delete \\
\hline Master & Berisi menu kategori dan menu kabupaten & Tambah, edit, delete \\
\hline Laporan & $\begin{array}{l}\text { Daftar warisan budaya yang terdata di } \\
\text { pustaka digital }\end{array}$ & Tambah, edit, delete \\
\hline
\end{tabular}

\subsection{Pengelolaan Menu pada Situs Riau Heritage Digital Library}

Cara pengelolaan dari ketiga menu tersebut dilakukan dengan mengklik nama menu, contohnya pengelolaan menu warisan budaya, klik menu warisan budaya maka akan ditampilkan layout seperti gambar 7. Pada menu ini admin dapat melakukan aksi penambahan data, edit data dan penghapusan data. Semua transaksi akan dicatat secara otomatis sesuai dengan tanggal yang berlaku di sistem.

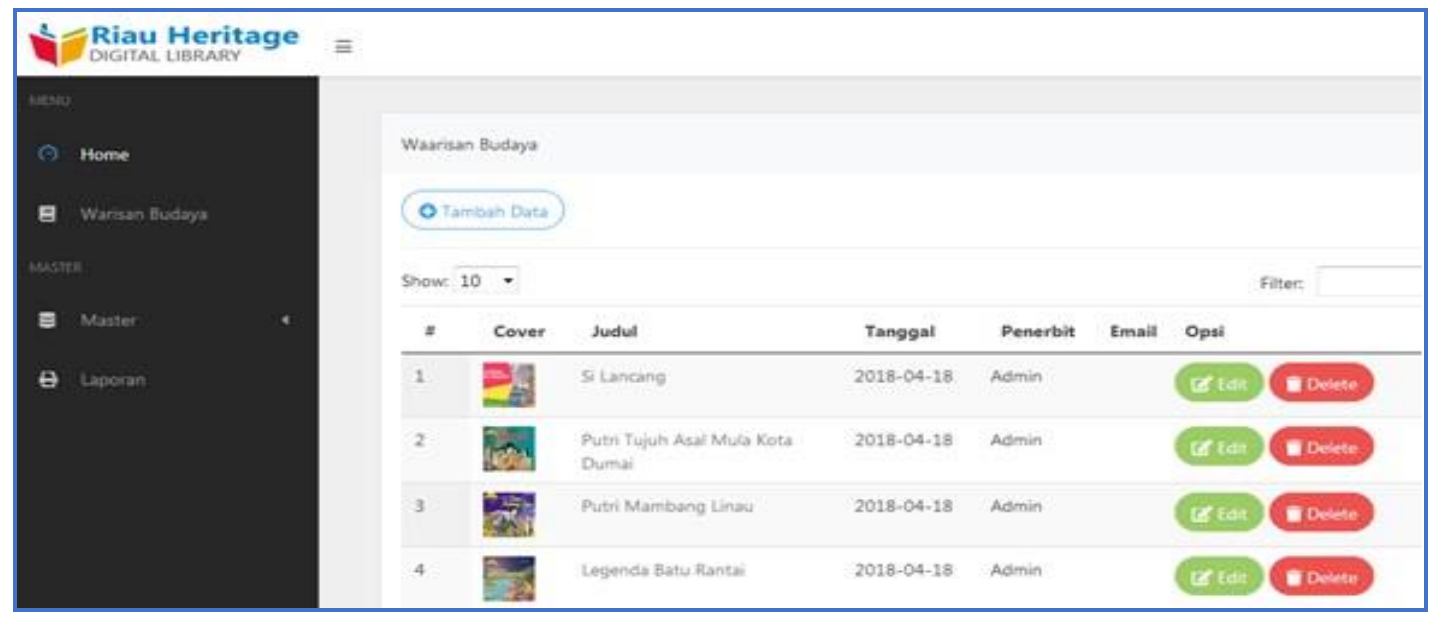

Gambar 7. Pengelolaan Menu Riau Heritage

\subsection{Pencarian Seluruh Daftar Riau Heritage Digital Library}

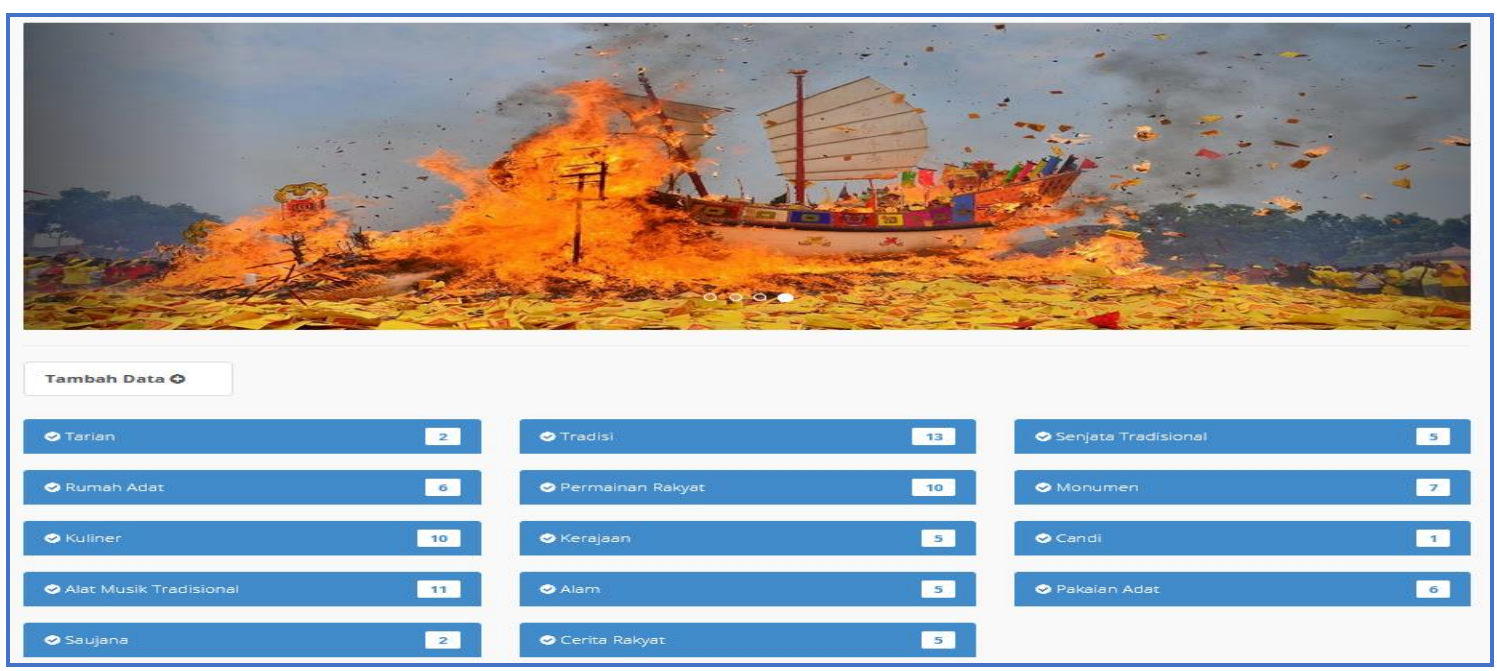

Gambar 8. Daftar Riau Heritage Digital Library berdasarkan Kategori Khusus 
Pencarian seluruh daftar Riau Heritage Digital Library ditampilkan pada gambar 8 diatas yang memperlihatkan daftar semua heritage yang dimiliki oleh provinsi Riau yang telah dikelompokkan berdasarkan kategori khusus. Terdapat 14 (empat belas) pengelompokkan warisan Riau yaitu tarian, tradisi, senjata tradisional, rumah adat, permainan rakyat, monumen, kuliner, kerajaan, candi, alat musik tradisional, alam, pakaian adat, saujana dan cerita rakyat. Pengelompokkan warisan Riau ini untuk lebih mempermudah pencarian yang dilakukan oleh pengguna sehingga proses pencarian menjadi lebih efisien dan efektif.

\subsection{Pencarian Daftar Riau Heritage Digital Library berdasarkan Kabupaten}

Pencarian daftar Riau Heritage Digital Library berdasarkan kabupaten dapat dilihat pada gambar 9. Terdapat 12 (dua belas) kabupaten/kota yang terdapat di provinsi Riau yaitu Kuantan Singingi, Indragiri Hulu, Indragiri Hilir, Pelalawan, Siak, Kampar, Rokan Hulu, Bengkalis, Rokan Hilir, Kepulauan Meranti, Pekanbaru dan Dumai. Setiap kabupaten/kota memiliki warisan budaya dan warisan alam masing-masing dengan karakteristik yang berbedabeda. Pada gambar 9 terlihat hasil pencarian warisan budaya dan warisan alam dari kabupaten Bengkalis yang memuat warisan tarian tradisional yaitu tari Zapin, alat musik tradisional yaitu Kompang, tradisi berupa Tenunan Kain Songket dan Festival Lampu Colok.

Informasi lengkap mengenai masing-masing hasil pencarian dapat dilakukan dengan cara mengklik nama pencarian (tombol aktif) dan diberikan deskripsi lengkap mengenai warisan yang dituju, misal dengan mengklik tombol zapin maka informasi lengkap mengenai tarian ini akan ditampilkan sehingga pengguna dapat mengetahui secara detail informasi mengenai tarian Zapin ini.

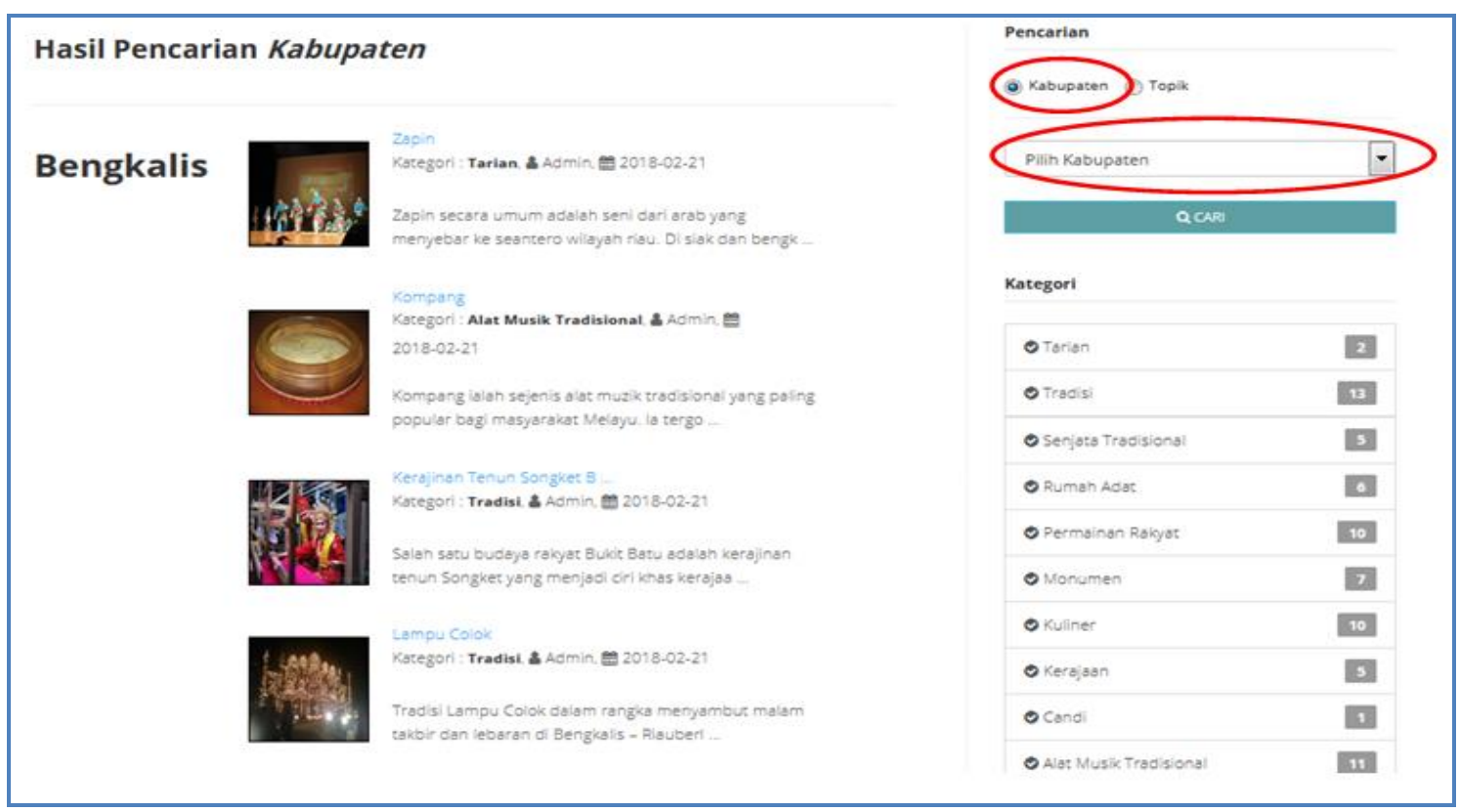

Gambar 9. Daftar Riau Heritage Digital Library berdasarkan Kabupaten

\subsection{Pencarian Daftar Riau Heritage Digital Library berdasarkan Kriteria}

Gambar 10 memperlihatkan pencarian daftar Riau Heritage Digital Library berdasarkan kategori kerajaan yang memperlihatkan sebagian kerajaan yang ada di provinsi Riau yaitu kerajaan Indragiri Hilir, kerajaan Kampar dan Kerajaan Pelalawan. Informasi lengkap mengenai kerajaan tersebut tersedia dengan cara mengklik nama kerajaan yang dituju, maka informasi lengkap mengenai kerajaan tersebut akan ditampilkan seperti diperlihatkan pada gambar 11. 


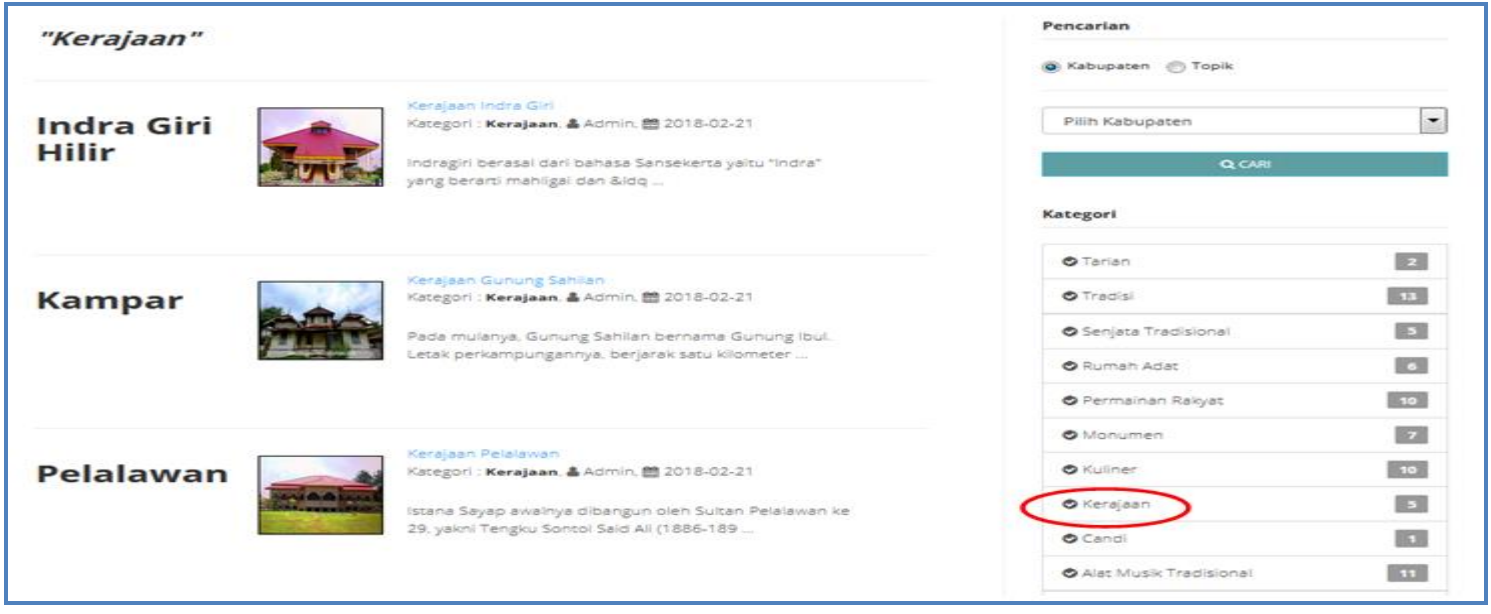

Gambar 10. Daftar Warisan Budaya Berdasarkan Kategori Kerajaan

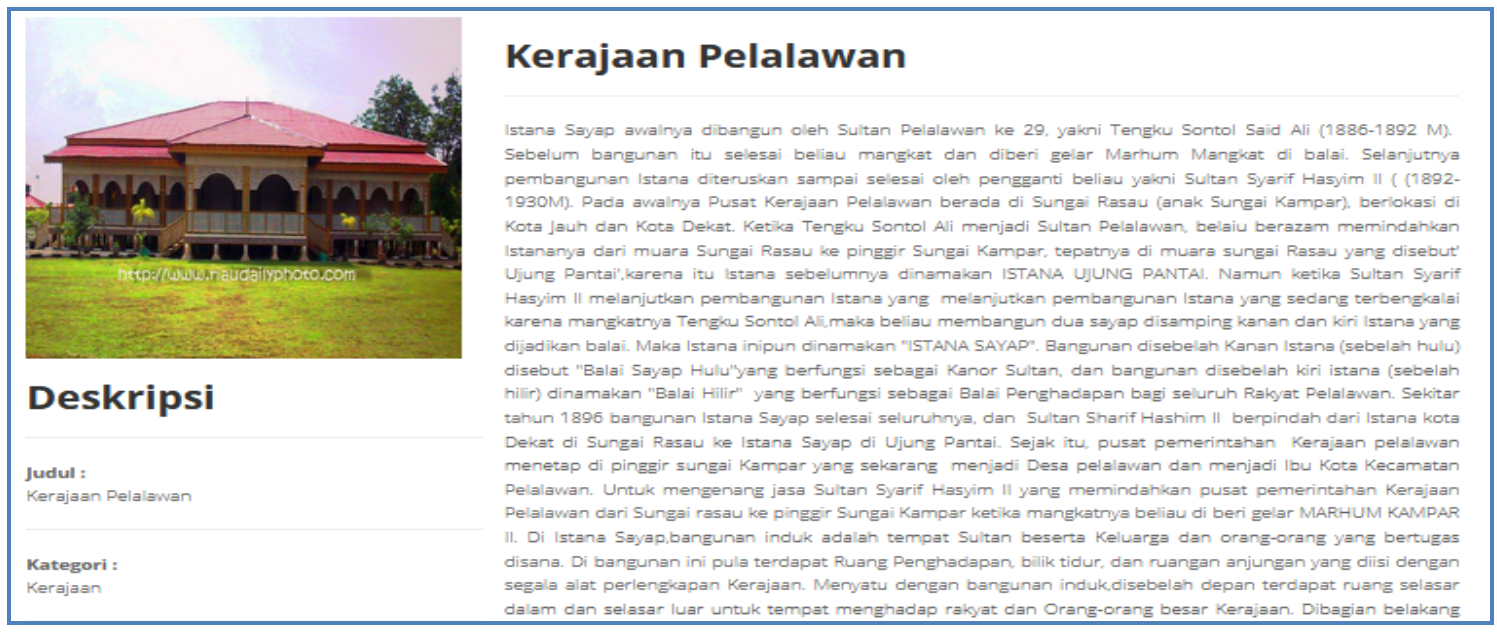

Gambar 11. Informasi Lengkap Kerajaan Pelalawan

\section{Kesimpulan}

Perancangan sebuah website Riau Heritage Digital Library telah selesai dibangun untuk mengatasi minimnya sarana yang bisa digunakan untuk menampung seluruh data dan informasi yang berkaitan dengan Riau Heritage. Situs ini mampu menampilkan seluruh warisan budaya dan warisan alam yang ada di provinsi Riau seperti bangunan kuno dan bersejarah, alam, candi, tarian dan musik tradisional, permainan rakyat, senjata tradisional, naskah kuno, upacara adat, perkawinan tradisional dan properti sejarah lainnya. Semua informasi dikemas dalam bentuk digitalisasi dan visual serta dapat di break down berdasarkan wilayah, tipe koleksi dan topik koleksi. Tambahan fasilitas lainnya adalah mitra dari masyarakat umum dapat juga mengirim dan menambahkan artikel, foto, video atau audio dari properti bersejarah Riau lainnya melalui validasi tim pengembang.

Dengan adanya situs Riau Heritage Digital Library lebih mempermudah transfer data dan informasi kepada generasi sekarang dan generasi selanjutnya. Selain itu juga bisa digunakan oleh wisatawan yang ingin berkunjung ke Riau dalam hal pencarian informasi mengenai Riau heritage mengingat heritage merupakan salah satu daya pikat wisatawan berkunjung ke suatu wilayah. Semua dokumen didigitalisasi dan bersama dokumen visual akan menghasilkan inventaris warisan budaya Riau sebagai bagian pusaka Indonesia. Selain itu agar terwujud rekam jejak sejarah, budaya dan peradaban masyarakat Riau sebagai masyarakat yang beradab dan bermartabat. 


\section{Ucapan Terimakasih}

Ucapan terimakasih disampaikan kepada Kementerian Riset, Teknologi dan Pendidikan Tinggi (Kemenristekdikti) melalui Direktorat Riset dan Pengabdian kepada Masyarakat yang telah mendanai penelitian ini melalui skema Penelitian Terapan Unggulan Perguruan Tinggi berdasarkan kontrak No. 3/E/KPT/2018.

\section{Daftar Pustaka}

[1] UNESCO. Charter on the Preservation of Digital Heritage. 2017. Link: http://portal.unesco.org/en/ev.php-URL_ID=17721\&URL_DO=DO_TOPIC, akses tanggal 25 Mei 2017.

[2] Oxford English Dictionary, link: https://www.oxfordlearnersdictionaries.com/definition/english/heritage, akses tanggal 28 Oktober 2018

[3] P. Howard. Heritage: Management, Interpretation, Identity. New York, Continuum, 2003. 288.

[4] Jaringan Pelestarian Pusaka Indonesia, ICOMOS Indonesia, Kementerian Kebudayaan dan Pariwisata RI. Piagam Pelestarian Pusaka Indonesia. Ciloto, 13 Desember 2003

[5] H. Rua, A. Gil. Automation in heritage - Parametric and associative design strategies to model inaccessible monuments: the case-study of eighteenth century Lisbon Águas Livres Aqueduct. Journal of Digital Applications in Archaeology and Cultural Heritage. 2014. Vol. 1, Issues 3-4. pp. 82-91

[6] A. J. Prieto, et al. Multiple linear regression and fuzzy logic models applied to the functional service life prediction of cultural heritage. Journal of Cultural Heritage. 2017. Vol. 27. pp. 20-35.

[7] M. C. Dieck, T. H. Jung. Value Value of augmented reality at cultural heritage sites: A stakeholder approach. Journal of Destination Marketing \& Management.2017. Vol. 6, Issue 2. pp. 110-117

[8] S. H. Nguyen, G. Chowdhury. Digital Library Research (1990-2010): A Knowlegde Map of Core Topics and Sub Topics. In C. Xing, F. Crestani, and A. Rauber (Eds.): ICADL 2011, LNCS 7008, pp. 367-371

[9] N. B. Ruparelia. Software Development Lifecycle Models. ACM SIGSOFT Software Engineering Notes. 2010. Vol. 35, Number 3. pp. 8-13.

[10] W. W. Royce. Managing the Development of Large Software Systems. In Proceedings, IEEE Wescon, August 1970. pp. 1-9 